\title{
Article
}

\section{Ion-exchange Behavior between Sodium Ion and Other Metal Cations in Hydrated Molybdenum Bronzes}

\author{
Noriyuki SOTANI, Yoshinori AYAMA, Bungo HATTA, Naoko TAKENOBU, and Kazuo EDA \\ Department of Chemistry, Faculty of Science, Kobe University, Tsurukabuto, Nada, Kobe 657-8501, Japan
}

(Manuscript submitted January 31, 2003; accepted April 18, 2003)

\begin{abstract}
Ion-exchange behavior between sodium ion and various metal cations (alkali, alkaline earth and a few transition metal cations) in hydrated molybdenum bronzes were investigated in $[\mathrm{NaCl}]+\mathrm{n}\left[\mathrm{M}(\mathrm{n}+) \mathrm{Cl}_{\mathrm{n}}\right]=1 \mathrm{M}$ solution. The selectivity of ion exchange was in the order of $\mathrm{Cs}$ $>\mathrm{Rb}>\mathrm{K}>\mathrm{Li}$ for alkalin metal and $\mathrm{Ba}>\mathrm{Sr}>\mathrm{Ca}>\mathrm{Mg}$ for alkaline earth metals. Transition metal cations gave similar ion exchange behavior to each other. The effect of the change in structure was hardly observed. The results suggest that the ion exchange behavior depends on the property of metal ions. The change in $\mathrm{MoO}_{3}$ interlayer spacing depends on the hydration energy, i.e. the surface charge density of metal cations. Hydrated sodium bronze can exchange with other metals and can extract metal ions in the solution. This property may be useful as the ion exchanger
\end{abstract}

\section{Introduction}

Metal ion inserted molybdenum trioxide called as "bronze", shows the different properties from $\mathrm{MoO}_{3}$ such as conductivity, intense color, metallic luster, and mixed valence state. Among them, there is a group of hydrated metal bronze.[1-4] Hydrated metal bronze, $\left[\mathrm{M}\left(\mathrm{H}_{2} \mathrm{O}\right)_{\mathrm{y} / \mathrm{x}}\right]_{\mathrm{x}} \cdot\left[\mathrm{MoO}_{3}\right]$, designated as Hy-M, is obtained theoretically according to eq.(1),

$$
(\mathrm{x} / \mathrm{n}) \mathrm{M}^{\mathrm{n}+}+\mathrm{xe}^{-}+\mathrm{yH}_{2} \mathrm{O}+\mathrm{MoO}_{3} \rightarrow\left[(1 / \mathrm{n}) \mathrm{M}^{\mathrm{n}+}\left(\mathrm{H}_{2} \mathrm{O}\right)_{\mathrm{y} / \mathrm{x}}\right]_{\mathrm{x}}\left[\mathrm{MoO}_{3}\right]^{\mathrm{x}-}
$$

where $\mathrm{M}$ is a metal cation $\left(\mathrm{Li}, \mathrm{Na}, \mathrm{K}, \mathrm{Rb}, \mathrm{Cs}, \mathrm{Mg}, \mathrm{Ca}, \mathrm{Sr}, \mathrm{Ba}, \mathrm{Co}\right.$, and $\mathrm{Ni}$ ) and $\mathrm{n}$ is charge number. $\mathrm{MoO}_{3}$ must be reduced before any of the guest cations are inserted. The hydrated sodium bronze, $\left[\mathrm{Na}^{+}\left(\mathrm{H}_{2} \mathrm{O}\right)_{\mathrm{y} / \mathrm{x}}\right]_{\mathrm{x}}\left[\mathrm{MoO}_{3}\right]^{\mathrm{x}-}$, is easily obtained using sodium dithionate, $\mathrm{Na}_{2} \mathrm{~S}_{2} \mathrm{O}_{4}$, which is a conventional reducing reagent for $\mathrm{MoO}_{3}$ [5-8]. Other hydrated metal bronzes are obtained only by the ion exchange from hydrated sodium bronze in ambient electrolyte solution, because of no useful alkali reagent for reduction except $\mathrm{Na}_{2} \mathrm{~S}_{2} \mathrm{O}_{4}$.

Hydrated sodium molybdenum bronze is expected to be an ion exchanger. Therefore, it is very useful to study the ion exchange behavior of metal ion in the solution with $\mathrm{Na}^{+}$ion. We tried to obtain hydrated metal bronzes by ion exchange. Hydrated metal bronzes should be obtained according to eq.(2),

$$
\left[\mathrm{Na}^{+}\left(\mathrm{H}_{2} \mathrm{O}\right)_{\mathrm{y} / \mathrm{x}}\right]_{\mathrm{x}}\left[\mathrm{MoO}_{3}\right]^{\mathrm{x}-}+(\mathrm{x} / \mathrm{n}) \mathrm{M}^{\mathrm{n}+} \rightarrow\left[(1 / \mathrm{n}) \mathrm{M}^{\mathrm{n}+}\left(\mathrm{H}_{2} \mathrm{O}\right)_{\mathrm{y} / \mathrm{x}}\right]_{\mathrm{x}}\left[\mathrm{MoO}_{3}\right]^{\mathrm{x}-}+\mathrm{xNa}^{+}
$$

This suggests that metal ion can be extracted by ion exchange with $\mathrm{Na}^{+}$ion.

\section{Experimental}

Preparation of hydrated sodium molybdenum bronze was described previously.[5] Hydrated metal bronzes 
were obtained from hydrated sodium bronze by ion exchange with $\mathrm{Na}$ ion. The starting material of hydrated sodium bronze was suspended at $303 \mathrm{~K}$ in the mixed solution of $\mathrm{NaCl}$ and metal chloride with the total concentration of $1 \mathrm{M}\left(\mathrm{M}=\mathrm{mol} \mathrm{dm}{ }^{-3}\right)$ and was stirred for overnight to homogenize. During the reaction nitrogen gas was passed through the solution to prevent oxidation of the product. The product was collected by suction filtration and was washed with distilled water until colorless. This product after washed is called as "WET" type. The WET type changed immediately to another phase on leaving in air. This is called as "VD" type.

TG-DTA studies were performed both in air and in nitrogen using a Mac Science TG-DTA 2000 with a heating rate of $10 \mathrm{~K} \mathrm{~min}^{-1}$. X-ray diffraction (XRD) patterns of the samples were obtained using a Mac Science MXP3 Xray diffractometer with $\mathrm{CuK} \alpha$ radiation $(40 \mathrm{KV}, 35 \mathrm{~mA})$. The contents of metal ions were measured with a Hitachi 180-80 atomic absorption spectrophotometer. The total content of $\mathrm{Mo}^{5+}$ was determined by redox titration method.[9]

\section{Results and Discussion}

The cation exchange was studied in the mixed solution of $\mathrm{NaCl}-\mathrm{M}(\mathrm{n}+) \mathrm{Cl}_{\mathrm{n}}$ having a total charge equivalent concentration of $1 \mathrm{M}\left(=[\mathrm{NaCl}]+\mathrm{n}\left[\mathrm{M}(\mathrm{n}+) \mathrm{Cl}_{n}\right]\right)$. Hy-Na(hydrated sodium) WET type, $\left[\mathrm{Na}_{0.25}\left(\mathrm{H}_{2} \mathrm{O}\right)_{n}\right]\left[\mathrm{H}_{\mathrm{y}} \mathrm{MoO}_{3}\right]$, was used as a starting material, because $\mathrm{Hy}-\mathrm{Na}(\mathrm{VD})$ was changed immediately to WET type in the solution. $\mathrm{Na}^{+}$ ion in $\mathrm{Hy}-\mathrm{Na}$ (WET) can be exchanged with other metal ions. Therefore, Hy- $\mathrm{Na}$ (WET) can act as an ion exchanger. In order to confirm the selectivity of ion exchange, the exchange behavior has been studied by the quantitative analysis of the ion exchange equilibrium. The selectivity of the exchanger is expressed in terms of selectivity coefficients. $[10,11]$ The ion exchange reaction between ion A in the solid and ion B in the solution is generally expressed as

$$
z_{B} \overline{A^{\tau_{A}}}+z_{A} B^{\bar{z}_{B}} \rightarrow z_{B} A^{\bar{A}_{A}}+z_{A} \overline{B^{z_{B}}}
$$

A bar indicates ionic species in the solid. At equilibrium, an equilibrium constant $K$ is expressed as,

$$
K=\frac{\alpha_{A}^{z_{B}} \cdot \overline{\alpha_{B}^{z_{A}}}}{\alpha_{B}^{z_{A}} \cdot \overline{\alpha_{A}^{z_{B}}}}
$$

where $\alpha$ is the activity. Then, $\alpha$ is expressed as $\alpha=f[A]$, where $[A]$ is the molarity and $f$ is an activity coefficient. Eq.(4) is converted to eq.(5).

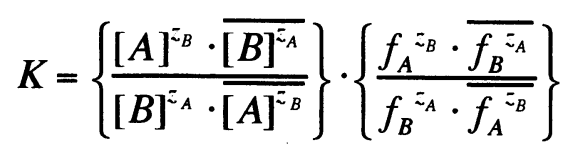

$K_{A}^{B}$ is the selectivity coefficient defined as eq.(6),

$$
K_{A}^{B}=\left\{\frac{[A]^{\bar{B}_{B}} \cdot \overline{[B]^{\sigma_{A}}}}{[B]^{-A} \cdot \overline{[A]^{\sigma_{B}}}}\right\}
$$

Replacing by ionic fraction, $x$, as total concentration is $1 \mathrm{M}$, eq.(6) is converted to eq.(7).

$$
K_{A}^{B}=\frac{x_{A}^{z_{B}} \cdot \overline{x_{B}^{z_{A}}}}{x_{B}^{i_{A}} \cdot \overline{x_{A}^{z_{B}}}}
$$




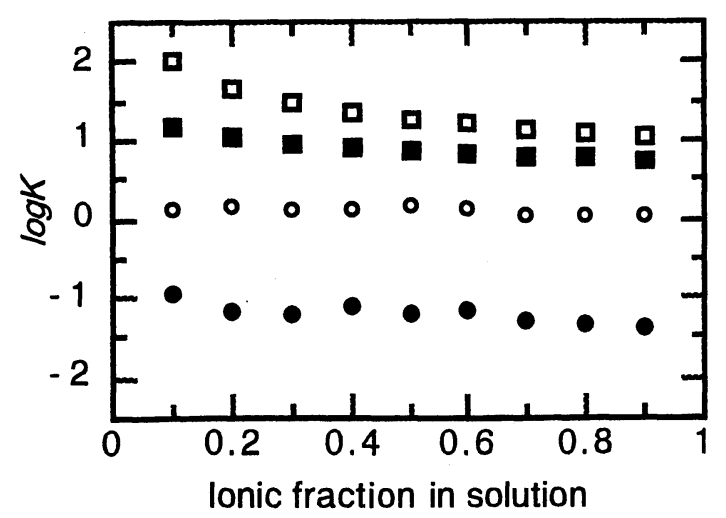

Fig. $1 \log K$ of alkali metal against ionic fraction in solution. $\mathrm{Li}$, $\mathrm{O}: \mathrm{K}, \mathbf{\square}: \mathrm{Rb}$, and $\square: \mathrm{Cs}$.

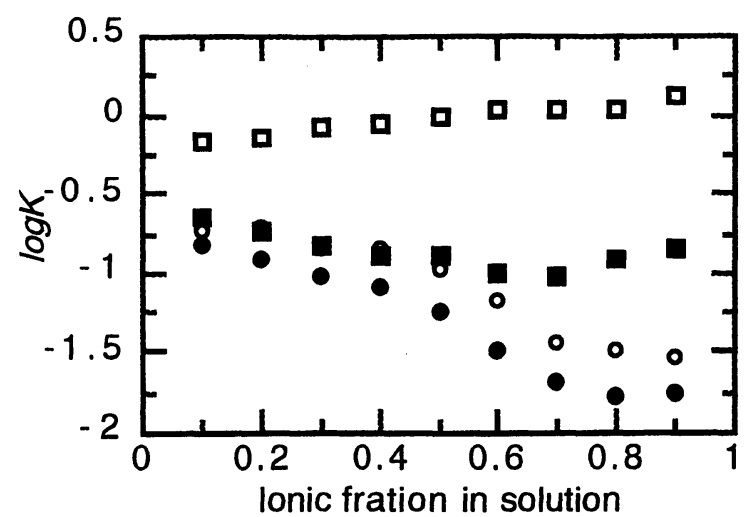

Fig. $2 \log K$ of alkali earth metal against ionic fraction in solution. $\mathrm{Mg}$, $\bigcirc$ : $\mathrm{Ca}, \mathbf{\mathrm { S }} \mathrm{Sr}$, and $\square: \mathrm{Ba}$.

We use $\log K_{A}{ }^{B}$ to evaluate the selectivity of ion exchange. If $\log K$ is positive, the ion exchange is easy to take place. While $\log K$ is negative, the ion exchange is difficult to occur. Figure 1 shows $\log K_{N a}{ }^{M}$ against ionic fraction of alkali metal ions. In the case of $\mathrm{Cs}$ and $\mathrm{Rb}$, as $\log K>0$, the exchange was easy to take place, while Li showed $\log K<0$. The fact that $\log K$ of $\mathrm{K}$ showed constant around zero for all ionic fraction ranges suggests that the reversible exchange between $\mathrm{Na}$ and $\mathrm{K}$ took place. The selectivity of alkali metal ion was in the order of $\mathrm{Cs}>\mathrm{Rb}$ $>\mathrm{K}>\mathrm{Li}$. The selectivity of alkaline earth metal ions is shown in Fig. 2, which gave two groups. The selectivity of

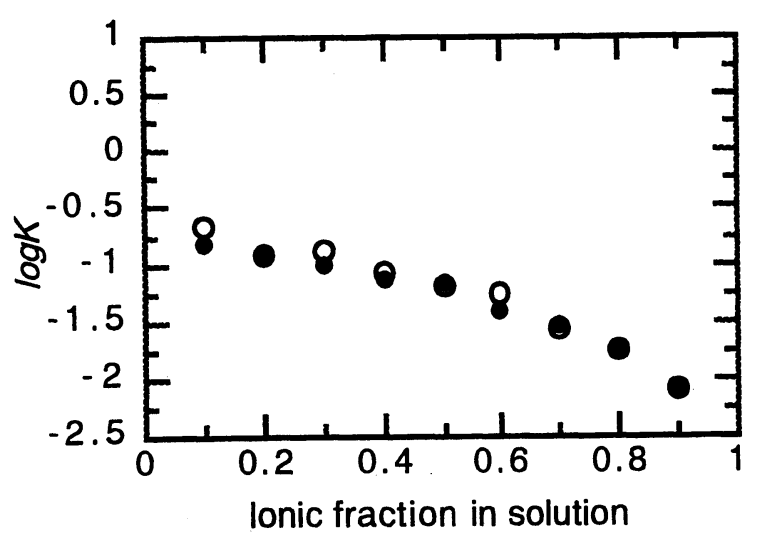

Fig. $3 \log K$ of transition metal against ionic fraction in solution. $\mathrm{Co}$ and $\mathrm{O}: \mathrm{Ni}$.
$\mathrm{Ba}$ gave nearly zero. This suggests that the reversible exchange should take place. While those of $\mathrm{Mg}, \mathrm{Ca}$, and Sr were negative and the exchange was difficult to take place. The order of selectivity was $\mathrm{Ba}>\mathrm{Sr}>\mathrm{Ca}>\mathrm{Mg}$. Figure 3 shows that the selectivity of $\mathrm{Co}$ and $\mathrm{Ni}$ was negative. Therefore exchange was difficult to take place.

Table 1 shows the amount of cation in the ion exchanged hydrated bronzes. $\mathrm{Na} / \mathrm{Mo}$ of $\mathrm{Hy}-\mathrm{Na}(\mathrm{WET})$ as the starting material was 0.25 . The amount of monovalent alkali metal ions exchanged was $0.22 \sim 0.24$ of $\mathrm{M} / \mathrm{Mo}$ and that of divalent cations was $0.09 \sim 0.12$ of $\mathrm{M} / \mathrm{Mo}$. In the case of divalent ions, the amount was about a half of monovalent ones to keep electrical charge balance. Lack of charge was compensated by protons inserted. Also lattice parameters of hydrated bronzes are listed in Table 1. According to these results, $a$ and $c$ axes keep constant, while $b$ axis changed. This suggests that the $\mathrm{MoO}_{3}$ layer spacings expanded or contracted along $b$ axis. The interlayer spacings may depend on the size of hydrated metal ions inserted. As the metal cations with large hydration energy can attract the large amount of hydrate waters, the metal cation with strong hydration energy may have the large size of hydrated metal cation. The hydration energy corelates with the surface charge density of metal cation, i.e. the size of metal cation. 
Table 1 Amount of metal ions and lattice parameters of hydrated bronzes.

\begin{tabular}{|c|c|c|c|c|}
\hline Bronze & M/Mo & $a / \mathrm{nm}$ & $b / \mathrm{nm}$ & $c / \mathrm{nm}$ \\
\hline \hline Hy-Li(WET) & 0.24 & 0.384 & 2281 & 0.374 \\
\hline Hy-Na(WET) & 0.25 & 0.385 & 2.292 & 0.374 \\
\hline Hy-K(WET) & 0.22 & 0.384 & 2.302 & 0.373 \\
\hline Hy-Rb(WET) & 0.23 & 0.385 & 2.282 & 0.374 \\
\hline Hy-Cs(WD)* & 0.23 & 0.384 & 1.989 & 0.373 \\
\hline Hy-Mg(WET) & 0.12 & 0.383 & 3.452 & 0.374 \\
\hline Hy-Ca(WET) & 0.10 & 0.385 & 2.865 & 0.373 \\
\hline Hy-Sr(WET) & 0.09 & 0.384 & 2.901 & 0.373 \\
\hline Hy-Ba(WET) & 0.09 & 0.381 & 2.688 & 0.372 \\
\hline Hy-Co(WET) & 0.11 & 0.385 & 3.434 & 0.373 \\
\hline Hy-Ni(WET) & 0.09 & 0.385 & 3.421 & 0.373 \\
\hline
\end{tabular}

*Hy-Cs(WET) was not obtained.

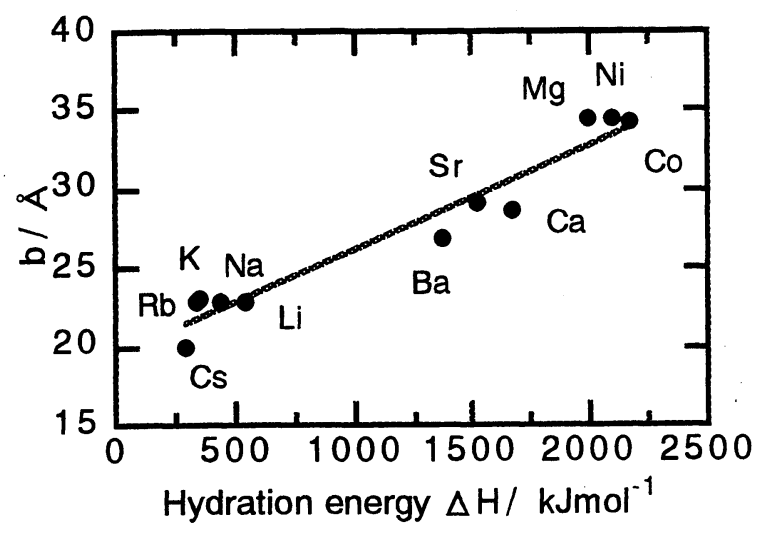

Fig. 4 Relation between $b$ and hydration energy
The $\mathrm{MoO}_{3}$ layer spacings along $b$ axis should depend on the hydration energy. Figure 4 shows the linear relation between $b$ and hydration energy. It is clear that the interlayer spacings closely depend on the size of hydrated metal cations.

Hydrated sodium bronze really extracts metal cations in the solution by ion exchange. Therefore, Hy-Na is expected to be the ion exchanger. The study on the exchange behavior in the mixted solution containing more than two kinds of metal cations is in progress.

\section{References}

1) R. S. Schollhorn, R. Kuhlman, and J. O. Besenhard, Mater. Res. Bull., 11, 83-90(1976).

2) D. Thomas and E. M. McCaron, III, Mater. Res. Bull., 21, 945-960(1986).

3) S. Son, F. Kanamaru, and M. Koizumi, Inorg. Chem., 18, 400-402(1979).

4) T. Iwamoto, Y. Itoh, K. Ohkawa, and M. Takahashi, Nippon Kagaku Kaishi, 1983, 272-276.

5) N. Sotani, K. Eda, and M. Kunitomo, J. Solid State Chem., 89, 123-129(1990).

6) M. Kunitomo, T. Kohmoto, Y. Fukuda, K. Eda, N. Sotani, and M. Kaburagi, Physics Letters A, 199, 103-106 (1995).

7) N. Sotani, T. Suzuki, K. Eda, M. Yanagi-ishi, S. Takagi, and F. Hatayama, J. Solid State Chem., 132, 330-336 (1997).

8) K. Eda, F. Hatayama, M. Kunitomo, T. Kohmoto, and N. Sotani, J. Mater. Chem., 4, 205-207(1994).

9) C. Choain and F. Marion, Bull. Soc. Chim. Fr., 1963, 212-212.

10) J.Inczedy, “AnalyticalApplication of Ion Exchange”, Pergamon Press,, New York(1966).

11) M. Seno, M. Abe, and T. Suzuki, “Ion Koukann”, Kodansha, Tokyou(1991). 